\title{
What are the challenges in migraine research? An interview with Parisa Gazerani
}

\author{
Parisa Gazerani*,1 \\ ${ }^{1}$ Biomedicine, Department of Health Science and Technology, Faculty of Medicine, Aalborg University Frederik Bajers Vej 3B,9220 \\ Aalborg East, Denmark \\ *Author for correspondence: Tel.: +45 9940 2412; gazerani@hst.aau.dk
}

Parisa Gazerani, PharmD, PhD, is an associate professor in the Faculty of Medicine, Aalborg University, Denmark. She completed postdoctoral training at the Faculty of Pharmaceuticals Sciences, The University of British Columbia, Canada with support from the International Brain Research Organization, International Association for the Study of Pain and the SparNord Foundation. Her passion and enthusiasm for understanding the pathogenesis of migraine and the potential role of non-neuronal components was subsequently supported by a prestigious Sapere Aude Young Elite Researcher Award from the Danish Ministry of Science in 2010. Her research interests include neuroscience, pain with a focus in migraine, biomarkers of neuroinflammation and development of novel treatments. Her research has resulted in more than 200 publications and several awards. Besides research, she teaches from undergraduate to PhD level, and has been awarded the title of 'teacher of the year'. She is a sought after reviewer for scientific journals, grant committees and PhD thesis evaluation. She is a member of several professional and scientific organizations. She is co-founder and head of research of a spin-off company, EMPros Bio, which is developing novel tools for the diagnosis and control of migraine. She also consults for several pharmaceutical and medicinal device companies.

First draft submitted: 3 December 2018; Accepted for publication: 3 December 2018; Published online: 15 January 2019

Keywords: biomarkers $\bullet$ glia $\bullet$ headaches $\bullet$ migraine $\bullet$ neuroinflammation $\bullet$ neurology $\bullet$ neuroscience $\bullet$ pain $\bullet$ trigeminal pain

\section{Can you begin by introducing yourself \& telling the readers a bit about your work to date?}

I was born into a family that encouraged my curiosity and learning. I was, and still am, enchanted by poetry and art. Science certainly did interest me in general as a child, but it became a core passion as I grew up. I still love reading and writing poetry, and feel that this has also influenced my writing style for scientific research papers. I was originally training to become a clinical pharmacist, but twists and turns along the way caused me to become fascinated by complex scientific questions. I joined a neurology department and became interested in studying migraine. For the last 2 years of my degree program, I balanced my classes with a research project that led to the publication of my first article on the correlation between migraine, histamine and Immunoglobulin E. After finishing my pharmacy degree, I spent 2 years to establish a therapeutic drug monitoring service for epilepsy patients at a Neuroscience Research Center. These experiences led me to become interested in learning more about neuroscience with a focus on pain mechanisms and biomarkers. Shortly thereafter, I found myself pursuing a PhD project at Aalborg University, Denmark; undertaking a project to model trigeminal pain and sensitization in humans. This project included a fascinating study to explore how botulinum neurotoxin A (BoNTA) can reduce pain in humans, a topic that continued to interest me long after my $\mathrm{PhD}$ ended. I enjoyed this research area so much that I could not leave this fascinating field behind. Therefore, I started a postdoctoral fellowship at The University of British Columbia, to learn and pursue more complex basic science research. Even though I knew nothing about molecular biology, electrophysiology and related skills, my postdoctoral supervisor, Dr Cairns, was still willing to take me on and to support me. My animal research showed that BoNTA decreases the sensitivity of muscle nociceptors within $3 \mathrm{~h}$ of injection. This study also demonstrated that BoNTA decreased muscle perfusion and extracellular glutamate 
release, which provided the first evidence of its analgesic mechanism. Dr Cairns' encouragement and advice kept me motivated to pursue my own ideas in these highly challenging projects. He also taught me about the necessity for rigorous scientific presentation and writing on research outcomes. Dr Cairns was a superb mentor. We still meet regularly to exchange ideas and continue to collaborate on projects.

After my postdoctoral fellowship, I returned to Aalborg University for a faculty position and to continue my research in migraine. During the past 8 years, I became highly interested in exploring the role of non-neuronal cells in migraine, in particular satellite glial cells of the trigeminal ganglion that wrap around the ganglion neurons. A cell-based platform was established and molecular markers of activation and inhibition of these cells were investigated. My collaborators and I found that cross talk exists between the satellite glial cells and trigeminal ganglion neurons that can cause peripheral sensitization and have investigated a number of transmitter substances and receptor mechanisms associated with this. We also examined whether some of these mechanisms play a role in headache in humans. More recently, I have been inspired by clinical cases of migraine to explore biomarker candidates by working in a translational fashion from cell to patients and back to focus on migraine signatures and footprints. The more I understand, the more I get fascinated and along the way, I spread my passion to my students and encourage more women to consider a career in the field of neuroscience.

\section{What influenced your decision to work in the field of pain research?}

I sensed an urge in me driven by my inner curiosity, passion and enthusiasm for finding better ways to prevent or treat migraine and pain in general. I considered starting medicine to specialize in pain management and continue to serve patients in the clinic. After reflection, I realized that the bigger problem was that there were very few effective treatments for pain. Thus, I decided to dedicate myself to research focused on understanding pain mechanisms and the search for better treatments. As my interest grew and matured, my research work progressed.

\section{Could you explain some of the challenges you faced when you started your research career \& how you overcame them?}

As a junior researcher, the biggest challenge I faced was a lack of funding for my research. At the time I started my faculty position, there was no start-up funding. However, I was fortunate to get funding from the Danish Research Council, which allowed me to start my independent research. The other challenge was access to modern research facilities equipped to do the kind of research that I wanted to pursue. To some extent, I have been able to form collaborations to overcome this. These challenges never stopped me from being excited about my research ideas. By staying focused on my research, I was able to find alternative ways to pave my path forward.

\section{Please tell our readers about the research you are currently carrying out}

My major research focus is still migraine. A few years ago, one of my collaborators and I identified unique miRNA and protein biomarkers of migraine. Building upon these initial findings in patients led to filing of a patent and then the establishment of a start-up company with the aim to develop diagnostic, prognostic and treatment monitoring tools for migraine. We have identified several interesting targets that can facilitate the understanding of neuro-inflammation, as well as peripheral and central sensitization; hallmarks of migraine pathogenesis.

\section{Following on from this, what are the challenges faced in migraine research \& how could they be overcome?}

Setting up and performing patient trials is not that straightforward. One of the biggest challenges remains the timely recruitment of patients into our studies. It is also difficult to access patients' samples. Establishment of biobanks is challenging and needs a lot of effort and clear communication for success. We often do pitches and present our research findings to enhance public awareness and to enhance motivation for trial participation. This can also facilitate support from organizations and funding agencies for research support.

\section{How do you think migraine research will develop in the next 5-10 years, \& what are your own research plans for the future?}

For migraine, this year has been an exciting year with the commercial release of the first two biologicals based on the role of calcitonin gene related peptide in migraine. This hypothesis-driven drug development has opened up the possibility of a new era in migraine management. Several other scientific achievements in the last decade may lead to the development of new migraine treatments. For example, one of these developments is a new appreciation of the 
role of non-neuronal cells in pain pathogenesis and transition from acute to chronic pain. Consequently, numerous molecular and cellular targets have been identified and products for targeting those are under development.

Neuromodulation for the treatment of headaches has also advanced. Stimulation of the vagal nerve and sphenopalatine ganglion have both shown promising results. It is likely that more research in this area will lead to widespread use of these and related techniques.

Proteomics and epigenomics of migraine have attracted more interest from pain researchers and headache specialist including myself. Research in biomarkers and their utility for drug development is exponentially progressing and will also be a major focus of my future research in migraine.

\section{Anything else you want to add?}

The migraine research field could benefit from more great minds. I have no hesitation to promote this field to all those who wish to enter a world of fascination, challenges and discoveries.

\section{Disclaimer}

The opinions expressed in this interview are those of the interviewee and do not necessarily reflect the views of Future Medicine Ltd.

\section{Financial \& competing interests disclosure}

The author has no relevant affiliations or financial involvement with any organization or entity with a financial interest in or financial conflict with the subject matter or materials discussed in the manuscript. This includes employment, consultancies, honoraria, stock ownership or options, expert testimony, grants or patents received or pending, or royalties.

No writing assistance was utilized in the production of this manuscript.

\section{Open access}

This work is licensed under the Attribution-NonCommercial-NoDerivatives 4.0 Unported License. To view a copy of this license, visit http://creativecommons.org/licenses/by-nc-nd/4.0/ 
